NBER WORKING PAPER SERIES

\title{
LUMPY CONSUMER DURABLES, MARKET POWER, AND ENDOGENOUS BUSINESS CYCLES
}

\author{
Kala Krishna \\ Cemile Yavas \\ Working Paper 8296 \\ http://www.nber.org/papers/w8296
NATIONAL BUREAU OF ECONOMIC RESEARCH
1050 Massachusetts Avenue
Cambridge, MA 02138
May 2001

\begin{abstract}
We are grateful to Ricardo Cavalcanti, Oded Galor, Susumu Imai, Christian Schultz, Neil Wallace, David Weil and Joe Zeira for useful comments. We have also benefited from the comments of participants at the Cornell-PSU macro workshop, and seminars at the Board of Governors of the Federal Reserve, the IMF, University of Texas, Austin, Rice University and the Hebrew University of Jerusalem. Krishna is grateful for support from the National Science Foundation. Part of this work was conducted while Krishna was a Lady Davis Professor at the Hebrew University. The views expressed herein are those of the authors and not necessarily those of the National Bureau of Economic Research.
\end{abstract}

(C) 2001 by Kala Krishna and Cemile Yavas. All rights reserved. Short sections of text, not to exceed two paragraphs, may be quoted without explicit permission provided that full credit, including (C) notice, is given to the source. 
Lumpy Consumer Durables, Market Power, and Endogenous Business Cycles

Kala Krishna and Cemile Yavas

NBER Working Paper No. 8296

May 2001

JEL No. E32, E13, E51, D11, D42

\section{$\underline{\text { ABSTRACT }}$}

This paper examines the role of lumpy consumer durables and market power in generating endogenous cycles which seem to be consistent with the facts. When goods are durable, past consumption choices determine the current market size which consists of consumers who have not purchased the good previously, and who have the income to make their potential demand effective. Larger past sales, ceteris paribus, thus naturally result in a smaller current market size and income. In this manner, the seeds of a downturn are sown in an upturn.

Kala Krishna

Department of Economics

523 Kern Graduate Building

Pennsylvania State University

University Park, PA 16802

and NBER

kmk4@psu.edu
Cemile Yavas

Pennsylvania State University

University Park, PA 16802 


\section{Introduction}

This paper examines the role of lumpy consumer durables and market power in generating endogenous cycles. The idea we model is simple. When goods are durable, past consumption choices determine the current market size which consists of consumers who have not purchased the good previously. Larger past sales, ceteris paribus, thus naturally result in a smaller current market size. In this manner, the seeds of a downturn are sown in an upturn.

The properties of the cycles predicted by our model are consistent with a number of empirical regularities. Among the stylized facts on business cycles are pro-cyclical real wages, counter-cyclical prices, and durable good consumption being more volatile than output. ${ }^{1}$ A more detailed discussion of the empirical implications can be found in Section 3.1.

Expenditure on consumer durables is often seen as a leading indicator for business cycles and there is considerable evidence that consumer durables play an important role in the business cycle. For example, Olney (1999) argues that the debt incurred for consumer durables, like cars, helped create the Great Depression. As consumers burdened with high debt cut spending, output fell as did factor demand, reducing profits and wages which in turn further reduced demand and this spiralled into the Great Depression. Gordon

\footnotetext{
${ }^{1}$ Stock and Watson (1999), Cooley and Prescott (1995), and King and Rebelo (1999) report that prices are counter-cyclical, and durable good consumption is pro-cyclical and volatile. Barsky, Parker and Solon (1994) and Bils (1987) argue that when measured correctly real wages are pro-cyclical.
} 
(1980) argues that the 1955 surge in the automobile market led a general boom in the economy.

Our work relates to three strands of literature: indivisibilities, endogenous business cycles, and durable good monopoly. The literature on indivisibilities has dealt with the non convex production sets created by indivisibilities, ${ }^{2}$ with indivisibilities in investment or R\&D leading to spurts of activity, ${ }^{3}$ and with indivisibilities in labor supply raising the intertemporal elasticity of labor supply. ${ }^{4}$ However, there has been little work on indivisibilities in consumption.

We model a a zero-one kind of indivisibility in consumption: individuals buy one unit or none and cannot resell the good which lasts for only two periods. This zero-one form is meant to reflect the idea that the good must be of a minimum size. ${ }^{5}$ In practice, there are ways to make such goods non-durable and divisible such as renting or sharing their services. However, to the extent that it is more costly to rent than buy and because of problems sharing durables, these are not perfect substitutes. ${ }^{6}$ For simplicity, we abstract from such alternatives.

\footnotetext{
${ }^{2}$ See Scarf $(1981 \mathrm{a}, \mathrm{b})$.

${ }^{3}$ See Caplin (1985) and Shleifer (1986).

${ }^{4}$ See, for instance, Rogerson (1988).

${ }^{5}$ It is not possible to downsize endlessly as a way of reducing the extent of lumpiness: after all, a refrigerator has to be of a minimum size to be able to hold the needed perishables and a car can only be so small.

${ }^{6}$ At low income levels, even clothing is seen as indivisible good. One of the most successful projects undertaken by the World Bank involved subsidizing purchases of wood stoves. The initial cost of such stoves, around 10 to 25 dollars, prohibited their widespread usage although they are more efficient than native stoves made of mud.
} 
The business cycle literature provides several models in which cycles may arise endogenously. One route is via dynamic models where, for some parameter values, the economy does not converge to a steady state, but to a limit cycle, see for example, Diamond and Fudenberg (1989). Cycles may also emerge through expectational effects which could be related to exogenous variables like "animal spirits" as in Howitt and McAfee (1992), or to endogenous variables like prices and interest rates as in Grandmont (1985). In these models, both cyclical as well as non-cyclical behavior is possible. A third route for cycles to arise is via persistent exogenous shocks which get propagated through the system as in the real business cycles literature. See King and Rebelo (1999) for a survey of this literature. ${ }^{7}$ In contrast to the above literature, endogenous cycles arise generically in our model. Past pricing decisions leads to current demand conditions, and this results in endogenous business cycles in the absence of any exogenous shocks or expectational effects.

The literature on durable goods has focused on the price path chosen by a durable good monopolist in a partial equilibrium setting. ${ }^{8}$ By assuming that consumers are infinitely lived and continually replenished, Conlisk, Gerstner and Sobel (1984) argue that pricing behavior of a durable good mo-

\footnotetext{
${ }^{7}$ There has been much criticism of standard RBC models in terms of their ability to generate cycles which match the data. Large shocks are needed to generate the needed supply response given the fairly low intertemporal supply elasticities usually estimated, and persistent shocks are needed to generate cycles.

${ }^{8}$ See, for example, Stokey (1979) and Bulow (1982).
} 
nopolist could exhibit cycles in a stationary environment due to endogenous fluctuations in market size.

We focus on the general rather than partial equilibrium implications. We also move away from the standard focus on inter temporal price discrimination by ensuring that consumers always prefer buying now to later.

The outline of the paper is as follows. In Section 2, we develop the goods and factor market equilibria. Section 3 looks at why endogenous cycles arise under the assumption that firms are identical. Section 4 generalizes our results to the case where firms are allowed to differ in the demand conditions they face. We also look at the role of income distribution and argue that a more equal distribution of income could make cycles deeper. Section 5 shows that allowing forward looking behavior on the producers' side or credit markets does not alter our basic results. Section 6 concludes. $^{9}$

\section{The Model}

This paper builds on the model developed in Krishna and Yavas (2000). The model is constructed to allow an elementary presentation. While its components are standard, the model itself is new.

\footnotetext{
${ }^{9}$ An Appendix, available on request, includes calculations for a special case which we use as an illustration.
} 


\section{$2.1 \quad$ Assumptions}

There are two types of goods in the economy: One divisible non durable, and for now, non storable, good produced under perfect competition, and a continuum of durable goods, indexed by $\theta \in[0,1]$, each produced by a profit maximizing monopolist. ${ }^{10}$ In each period, a new set of individuals arrives in the economy. Each individual lives for two periods. In each period of his life he derives utility from the consumption of the non durable good and of a specific type of durable good. We assume that used durables cannot be resold. ${ }^{11}$ Thus, consumers who buy the durable good in the second period of their lives get only one period of use.

Individuals are heterogenous in two dimensions. Individual $(\theta, \gamma)$ has a potential demand for one unit of the durable good $\theta \in[0,1]$ and his productivity is $\gamma \in[0,1]$. We assume that each consumer derives utility $V$ each period from his durable good, and that $V$ is large. Thus, he would purchase the durable good as soon as he could even if prices are expected to fall in the following period. This, of course, makes indirect utility discontinuous: consumers who are just able to buy the good are significantly better off than those with a slightly smaller income. ${ }^{12}$

\footnotetext{
${ }^{10}$ It should be possible to generalize this to oligopoly at the cost of some complexity.

${ }^{11}$ This could occur beacuse of transactions costs or the lemons' problem associated with resale.

${ }^{12}$ Although we assume below that $V$ is very high, that agents live for only two periods, and that the non durable good has constant marginal utility, these assumptions are made for simplicity. Diminishing marginal utility and a low $V$ results in some of the non durable good being purchased before the durable one making the indirect utility function continuous, though non convex. See Ng (1965). This would affect the exact form of the
} 
At each point of time, new consumers have an equal probability of having a potential demand for any $\theta$ so that there is a uniform distribution over $\theta$. We assume throughout that $\gamma$ and $\theta$ are independently distributed, and these distributions are time invariant. This ensures that all monopolists face the same problem if they inherit the same set of old consumers. The set of consumers who have a demand for the durable good $\theta$ are of measure zero relative to the set of all consumers. Thus, the pricing behavior of a monopolist does not have any general equilibrium effects. ${ }^{13}$ Durable good firms are monopolists, and therefore they set prices to maximize their profits. Thus, there tends to be too little of the durable good made.

We will use Assumption 1 below whenever concreteness is called for, and will draw the diagrams given this assumption. However, we present the result in a manner that shows they are more generally valid.

Assumption 1 New individuals are distributed uniformly over the unit square in each period with unit density.

\subsection{Factor Market}

Labor is the only factor of production in the economy. We normalize the size

of each generation at unity. As there are two cohorts, the size of the labor demand curve facing producers but not its nature. Similarly, allowing many generations of agents would just increase the complexity of the model and not affect the basic results.

${ }^{13}$ The assumption that there are a continuum of firms and agents removes the familiar "Numeraire Problem" in the literature. It makes the choice of a numeraire irrelevant as no individual incorporates the general equilibrium effect of his actions into his decision making. 
force at any given period is 2 . Workers with productivity $\gamma$ make $\gamma$ units of the non durable good and they produce $\alpha \gamma$ units of output in durables. Workers in the durable good sector are compensated according to a piece rate wage, $w$. We take the non durable good to be the numeraire. A worker with productivity $\gamma$ will have an earning of $\gamma$ in the non durable good sector. The same worker will produce $\alpha \gamma$ units of output in the durable good sector, and earn $\alpha \gamma w$. For both goods to be produced in equilibrium the wage has to be equal to $\frac{1}{\alpha}$. If the piece-rate wage in durables, $w$, is greater than $\frac{1}{\alpha}$, then all workers prefer to work making durables. Marginal cost of production in the durable good sector is constant at the piece rate wage, so $c=\frac{1}{\alpha}$. Note that the allocation of labor between the two sectors will be determined by the demand for labor in the durable good sector.

\section{Assumption $2 \quad \alpha>1$.}

As explained later, this assumption ensures that the durable good sector is viable.

\subsection{Goods Market}

To begin with we focus on the symmetric case, and assume that consumers cannot save or borrow so that consumers spend their entire income in each period. ${ }^{14}$ An individual's income consists of two components. The first component is labor earnings. As discussed in the previous section, this depends

\footnotetext{
${ }^{14}$ As shown in Section 5.2, this assumption is not central.
} 
on the productivity of the individual, with higher productivity individuals earning more. The second component of the income is the profit share. For concreteness we focus on two extreme cases. These are described as Assumption $3(a)$ and $3(b)$ below.

Assumption 3(a) Profits accrue only to consumers with very high values of $\gamma$.

In this case firms choose not to sell only to the very rich as they can at most charge them $V$ and they are small in number, but to the broader market.

Assumption 3(b) Profits are equally distributed across all individuals in the economy.

In this case each individual is entitled to $\frac{1}{2} \Pi$ as his profit share as the total population (labor force and hence consumers) in the economy is 2 .

Let $P$ be the price of a durable good. Let $\Pi(\gamma)$ denote the profit share for an individual with productivity $\gamma$. Thus, an individual with productivity $\gamma$ has income of $\Pi(\gamma)+\gamma$ so that he will purchase his durable good if

$$
P \leq \Pi(\gamma)+\gamma
$$

assuming that he does not already have it. The balance of his income is spent on the non durable good. 
The demand function facing a typical durable good firm given the proportion of young consumers served in the previous period, $\lambda_{t-1}$, and expected aggregate profits of $\Pi_{t}$ is denoted by $D\left(P, \Pi_{t}, \lambda_{t-1}\right)$. Figures $1(a)$ and $(b)$ depict demand under our standing assumptions and Assumption 3(a) and (b) respectively.

First consider what happens if there are no old consumers, i.e., $\lambda_{t-1}=1$, and aggregate profits are zero, i.e., demand is $D(P, 0,1)$. This is depicted in Figure 1 by the line $D d$ which gives the proportion of young individuals with a productivity higher than the price, $P$. If profits exist and go only to the most productive, who are a small part of the population, then only their demand could be affected by changes in $\Pi$. Willingness to pay equals the lower of total earnings and $V$. If earnings exceed $V$ for all these agents, demand is unaffected as depicted in Figure 1(a) by VJTD.

If profits are equally distributed, changes in $\Pi$ move the demand curve vertically as $\frac{\Pi}{2}$ is added to each individual's income and his willingness to pay for the durable good. At a price of $\frac{\Pi}{2}$ all individuals can afford the durable good, and as price falls below $\frac{\Pi}{2}$ there are no further increases in demand. Hence we obtain a demand curve with a vertical segment as depicted in Figure $1(b)$ as EeD.

The existence of some old individuals who have not previously purchased the durable good causes a kink in the demand curve. The kink occurs at the point on $D(P, \Pi, 1)$ vertically above $\lambda_{t-1}$, that is, at $F$ in Figure 1 . The 
Figure 1: The Demand Curve
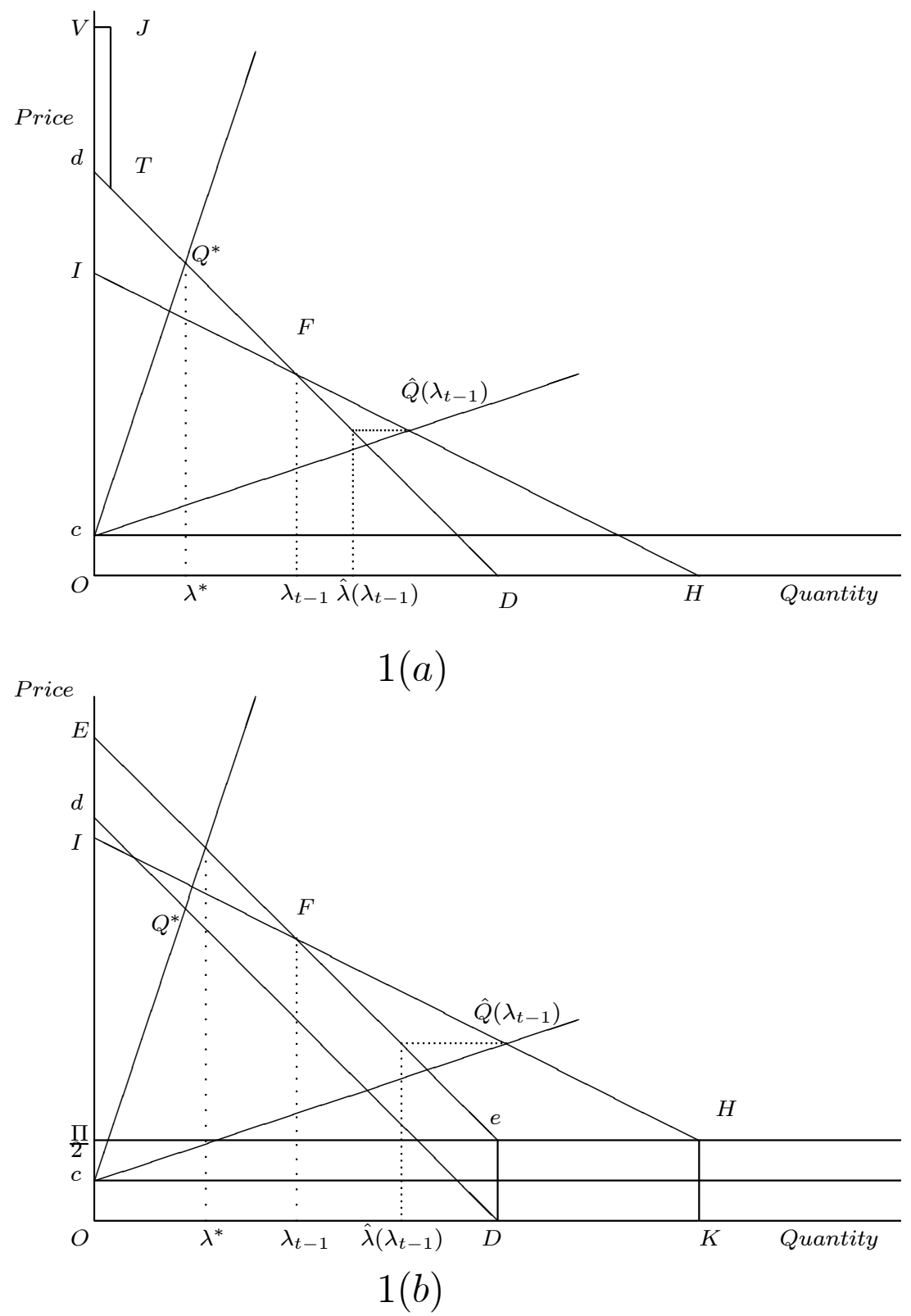
demand curve intersects the horizontal axis at $\left(2-\lambda_{t-1}\right)$. At prices below the kink, a unit reduction in the price level will result in twice the increase in the demand relative to that above the kink. The resulting demand curve, $D($.$) , is given by V J T F H$ in Figure $1(a)$ and $E F H K$ in Figure $1(b)$ and is the maximum of the two curves, VJTD and $I H$ in Figure 1(a) and EeD and $I H K$ in Figure $1(b)$. We denote the steeper curve where only the young are served, by $D^{*}($.$) , and the flatter one by \hat{D}($.$) .$

\section{Symmetric Equilibrium}

The endogenous variables in the system at time $t$ consist of the profits earned by each firm, denoted by $\pi_{t}$, the proportion of young individuals served, denoted by $\lambda_{t}$, and the price charged by firms making the durable good, $P_{t}$. In this section we assume that the proportion of young consumers served in period $t-1, \lambda_{t-1}$, is the same for all firms. This assumption is relaxed in Section 4 .

It is easy to derive the profit maximizing choice of the firm for given levels of aggregate profits, $\Pi_{t}$, and $\lambda_{t-1}$. Since there is a unit mass of identical firms in this model, the profits of each firm equal aggregate profits in the symmetric equilibrium. Setting these equal gives the profits in symmetric equilibrium at time $t$. Knowing the equilibrium level of profits then enables one to find the remaining endogenous variables including the state variable in the next period, $\lambda_{t}$. 
Consider the output choice of an individual firm at a given level of $\lambda_{t-1}$ and $\Pi$. There are three candidates for the profit maximizing output choice of each monopolist. Firms never choose to serve the whole market as it is not profitable as argued later. Thus, his optimal choice must lie either along the flatter part of the demand curve, or the steeper part of the demand curve.

Let $\pi\left(\Pi, \lambda_{t-1}\right)$ be the profits along $D($.$) , while \pi^{*}(\Pi)$ and $\hat{\pi}\left(\Pi, \lambda_{t-1}\right)$ denote the profits along $D^{*}($.$) and \hat{D}($.$) respectively. { }^{15}$ Demand is given by $D^{*}($. for high prices and by $\hat{D}($.$) for lower ones. An increase in \lambda_{t-1}$ increases the region over which $D^{*}($.$) is relevant as it shifts \hat{D}($.$) down vertically, but does$ not affect the level of $D^{*}($.$) . Note that demand becomes more elastic, and$ $\pi_{P}$ jumps up at the kink. Since $\pi_{P}$ along both $D^{*}($.$) and \hat{D}($.$) is downward$ sloping due to concavity of $\pi^{*}$ and $\hat{\pi}$, the first order condition, $\pi_{P}=0$, can never be satisfied at the kink. In other words, profits are maximized either along $D^{*}($.$) , above the kink, or along \hat{D}($.$) , below the kink, but never at the$ kink.

Figure 2(a) and $(b)$ depict $\pi^{*}(\Pi)$ and $\hat{\pi}\left(\Pi, \lambda_{t-1}\right)$ under Assumption 3(a) and (b) respectively.

Lemma 1 Under Assumption $3(a)$, both $\pi^{*}(\Pi)$ and $\hat{\pi}\left(\Pi, \lambda_{t-1}\right)$ are independent of $\Pi$ and hence weakly convex in $\Pi$. Under Assumption $3(b)$ both $\pi^{*}(\Pi)$ as well as $\hat{\pi}\left(\Pi, \lambda_{t-1}\right)$ are increasing functions of aggregate profits with slopes

\footnotetext{
${ }^{15} \mathrm{We}$ will use the following convention from here on to simplify the notation. The absence of $P$ as a variable indicates that the function is a value function as $P$ has been maximized out.
} 
Figure 2: Symmetric Equilibrium

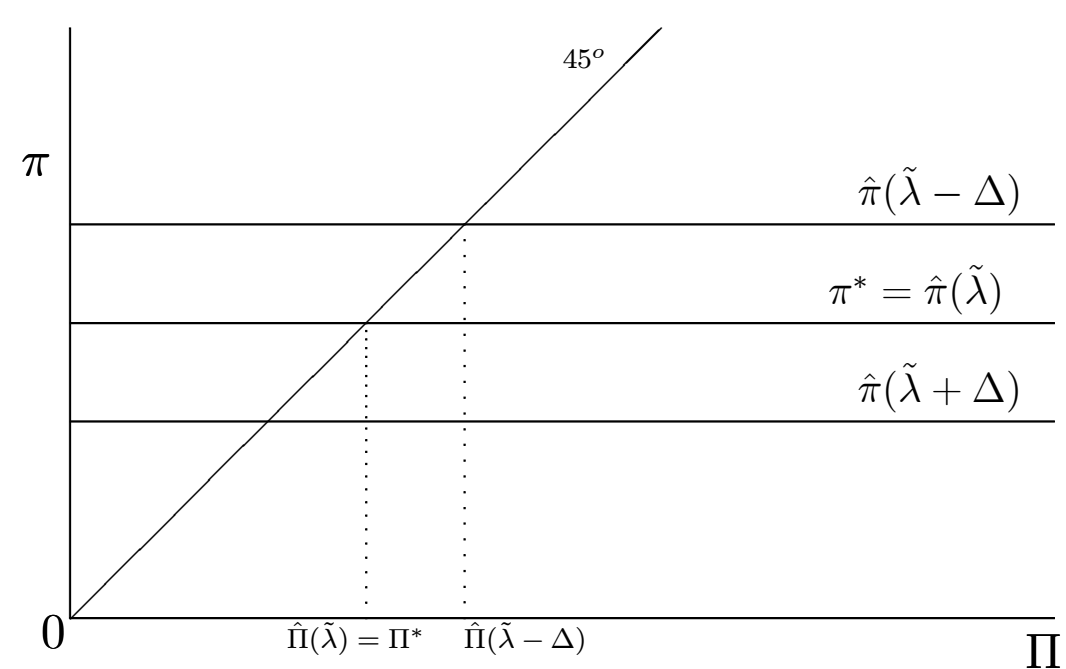

(a)

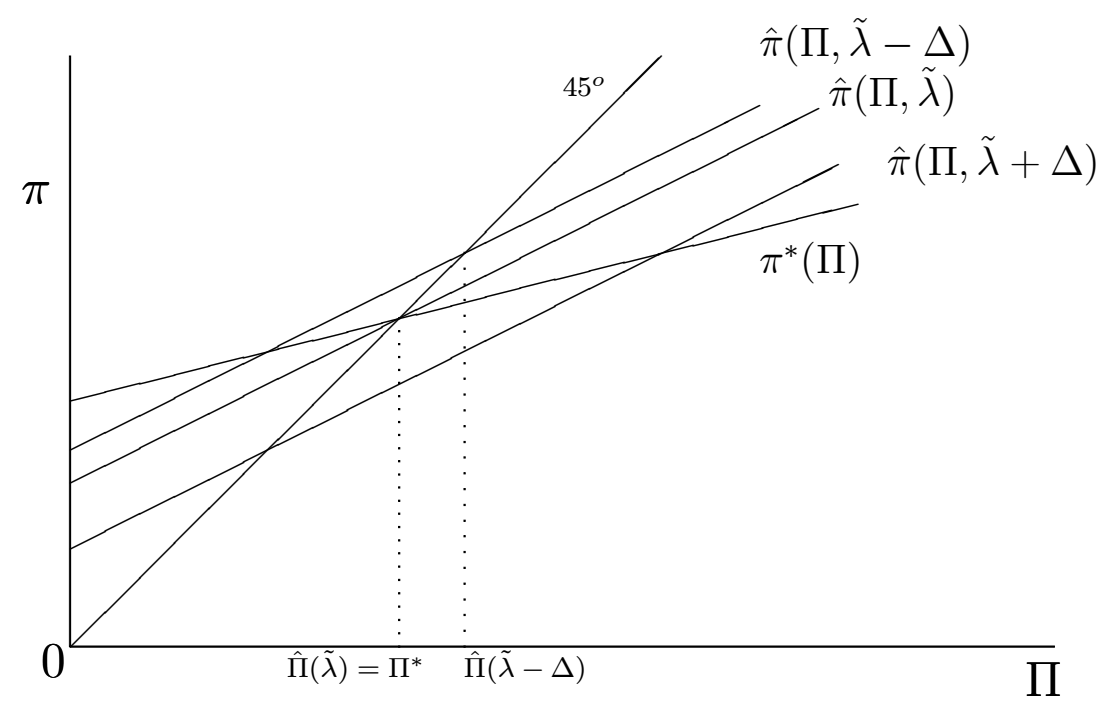

(b) 
less than unity, are convex in $\Pi$, and $\hat{\pi}\left(\Pi, \lambda_{t-1}\right)$ is steeper than $\pi^{*}(\Pi)$. Given Assumption 2, both have positive intercepts.

Proof: Let $P^{*}(Q, \Pi), \hat{P}\left(Q, \Pi, \lambda_{t-1}\right)$ and $P\left(Q, \Pi, \lambda_{t-1}\right)$ denote the inverse demand curves corresponding to $D^{*}(),. \hat{D}($.$) and D($.$) , respectively. An$ increase in $\Pi$ has no effect on demand under Assumption 3(a). Hence in Figure $2(a), \pi^{*}(\Pi)=\pi^{*}$ and $\hat{\pi}\left(\Pi, \lambda_{t-1}\right)=\hat{\pi}\left(\lambda_{t-1}\right)$ are horizontal. For high (low) $\lambda_{t-1}, \pi^{*}$ exceeds (falls short of) $\hat{\pi}\left(\lambda_{t-1}\right)$. As $\lambda_{t-1}$ rises, $\hat{\pi}\left(\lambda_{t-1}\right)$ falls. At $\lambda_{t-1}=\tilde{\lambda}$ the two lines coincide.

Under Assumption 3(b) an increase in profits shifts demand upward by $\frac{\Pi}{2}$. Firms choose $Q=Q\left(\Pi, \lambda_{t-1}\right)$ to maximize $\pi\left(Q, \Pi, \lambda_{t-1}\right)$. Using the envelope theorem gives

$$
\begin{aligned}
\frac{d \pi\left(\Pi, \lambda_{t-1}\right)}{d \Pi} & =\frac{\partial}{\partial \Pi}\left(\left(P\left(Q, \Pi, \lambda_{t-1}\right)-c\right) Q\right) \\
& =\frac{\partial P\left(Q, \Pi, \lambda_{t-1}\right)}{\partial \Pi} Q \\
& =\frac{1}{2} Q .
\end{aligned}
$$

If there were no sales in the previous period, then sales would be at most equal to 2 . If sales were at this maximum possible level, profits would rise one for one with aggregate profits. However, sales are less than this maximum so that both $\pi^{*}(\Pi)$ and $\hat{\pi}\left(\Pi, \lambda_{t-1}\right)$ are flatter than the $45^{0}$ line as depicted in Figure 2(b). ${ }^{16}$

\footnotetext{
${ }^{16}$ Note that if a firm sells to the entire market when aggregate profits are zero, then individual profits must be negative since price is zero and cost is positive. This results in a negative intercept for the individual profit curve and no intersection with the $45^{\circ}$ line in Figure 2.
} 
The profit maxima along $\hat{D}$ and $D^{*}$ lie along rays emanating from $c$ as drawn in Figure 1. ${ }^{17}$ Suppose that for a given level of aggregate profits, the profits along $\hat{D}$ and $D^{*}$ are equal, so that the same iso-profit contour is tangent to both, ${ }^{18}$ that is in Figure $2, \pi^{*}($.$) and \hat{\pi}($.$) curves intersect$ at this profit level. Then output along $\hat{D}$ exceeds that along $D^{*}$ so that the slope of $\hat{\pi}($.$) exceeds that of \pi^{*}($.$) at this point. From this$ it also follows that there can be at most one intersection between the two as depicted in Figure 2 since multiple intersections would violate this slope relation. Therefore, profits are given by $\hat{\pi}\left(\Pi, \lambda_{t-1}\right)$ above the intersection point, and by $\pi^{*}(\Pi)$ below the intersection point and $\pi($. is the maximum of $\pi^{*}($.$) and \hat{\pi}($.$) . Both \pi^{*}($.$) and \hat{\pi}($.$) are convex in$ $\Pi$ since output rises with $\Pi$ under assumption $3(b)$ and is unchanged under assumption 3(a). Since the maximum of convex functions remains convex, $\pi($.$) , is convex as well.$

The vertical intercept of the demand function is unity if there are no aggregate profits. If $\alpha \leq 1$, then costs exceed this intercept so that the optimal production level is zero and profits along both demand curves are negative at zero aggregate profits. In conjunction with profits being

\footnotetext{
${ }^{17}$ In the absence of the linearity ensured by Assumption 1, these rays are replaced by the profit expansion paths which would trace out the profit maximizing points along $D^{*}($.$) and$ $\hat{D}($.$) as aggregate profits rise. Individual profits are convex in aggregate profits because$ when profit expansion paths are upward sloping output rises with increases in aggregate profits.

${ }^{18}$ Isoprofit contours are rectangular hyperbolas emanating from a height $c$ on the vertical axis.
} 
flatter than the $45^{0}$ line, this means that there is no positive aggregate profit level at which the two intersect so that the durable good sector is not viable. If $\alpha>1$, as assumed, then these intercepts are positive so that an intersection in the positive quadrant is ensured and the durable good sector is viable.

\section{Proposition 1 There is a unique equilibrium profit level.}

Proof: Positive intercepts, together with $\pi_{\Pi}^{*}(\Pi) \leq \hat{\pi}_{\Pi}\left(\Pi, \lambda_{t-1}\right)<1$ under both Assumption 3(a) and (b) ensures a unique intersection of $\pi\left(\Pi, \lambda_{t-1}\right)$ and the $45^{\circ}$ line and hence a unique consistent level of profits denoted by $\Pi\left(\lambda_{t-1}\right)$. Under Assumption 3(a), profits of a single firm are independent of aggregate profit levels while under Assumption 3(b), they depend on aggregate profit levels.

Now we show that the equilibrium must involve cycles. As the proportion of old consumers rises so does the profit from serving them, i.e., as $\lambda_{t-1}$ falls $\hat{\pi}\left(\Pi, \lambda_{t-1}\right)$ shifts upward. As a result, in equilibrium, profits are maximized along $\hat{\pi}\left(\Pi, \lambda_{t-1}\right)$ for $\lambda_{t-1}<\tilde{\lambda}$ and along $\pi^{*}(\Pi)$ for $\lambda_{t-1}>\tilde{\lambda}$. Thus, in Figure 2 , equilibrium profits fall as $\lambda_{t-1}$ rises for $\lambda_{t-1} \leq \tilde{\lambda}$, and they are constant at $\Pi^{*}$ for $\lambda_{t-1}>\tilde{\lambda}$. At $\lambda_{t-1}=\tilde{\lambda}, \hat{\pi}\left(\Pi, \lambda_{t-1}\right)$ and $\pi^{*}(\Pi)$ intersect along the $45^{0}$ line. Similarly, output falls with increases in $\lambda_{t-1}$ for $\lambda_{t-1} \leq \tilde{\lambda}$ and is unaffected by $\lambda_{t-1}$ for $\lambda_{t-1}>\tilde{\lambda}$.

In Figure 1 this corresponds to output and profits in equilibrium being obtained from the intersection of $D^{*}($.$) and the ray through c$ associated with 
$D^{*}($.$) for high values of \lambda_{t-1}$ and from the intersection of $\hat{D}($.$) and the ray$ through $c$ associated with $\hat{D}($.$) for low enough \lambda_{t-1}$. The switchover occurs at $\lambda_{t-1}=\tilde{\lambda}$. When $\lambda_{t-1}=\tilde{\lambda}$, maximizing profits along $\hat{D}($.$) and D^{*}($.) yields the same level of profits. Hence the iso-profit contour is tangent to both $\hat{D}($.) and $D^{*}($.$) .$

A monopolist's problem can also be thought of as choosing the proportion of the young served in the current period, $\lambda_{t}$, as a function of the young served in the previous period, $\lambda_{t-1}$. This gives us a relation between $\lambda_{t}$ and $\lambda_{t-1}$ which we denote by $\lambda_{t}\left(\lambda_{t-1}\right)$. As usual, the proportion of young served depends on whether the price chosen is along $D^{*}($.$) or \hat{D}($.$) , and \lambda_{t}^{*}$ or $\hat{\lambda}_{t}$ correspond to the value of $\lambda_{t}\left(\lambda_{t-1}\right)$, respectively. Next we proceed to the properties of this relationship.

\section{Lemma 2}

$$
\begin{aligned}
& \lambda_{t}\left(\lambda_{t-1}\right)=\lambda^{*}<\lambda_{t-1} \text { for } \lambda_{t-1} \geq \tilde{\lambda} \\
& \lambda_{t}\left(\lambda_{t-1}\right)=\hat{\lambda}\left(\lambda_{t-1}\right)>\lambda_{t-1} \text { for } \lambda_{t-1} \leq \tilde{\lambda}
\end{aligned}
$$

and

$$
\frac{d \hat{\lambda}\left(\lambda_{t-1}\right)}{d \lambda_{t-1}}>0
$$

Proof: If $\lambda_{t-1}<\tilde{\lambda}$, equilibrium profits are given by the intersection of $\hat{\pi}\left(\lambda_{t-1}, \Pi\right)$ and the $45^{0}$ line. Firms choose to price below the kink in Figure 1 and to serve both the young and the old. Output is given by the intersection of the flatter ray through $c$ and $\hat{D}($.$) . The fraction of young$ 
served at this price is derived by going back to $D^{*}($.$) and is denoted by$ $\hat{\lambda}\left(\lambda_{t-1}\right)$. Output exceeds the share of young consumers served as both the young and old are served. Note that $\hat{\lambda}\left(\lambda_{t-1}\right)>\lambda_{t-1}$ as the firm will never price near the kink. As $\lambda_{t-1}$ falls, output rises but $\hat{\lambda}$ falls!

When $\lambda_{t-1}>\tilde{\lambda}$, equilibrium profits are given by the intersection of $\pi^{*}\left(\lambda_{t-1}, \Pi\right)$ and the $45^{0}$ line so that profits, output and $\lambda_{t}$ are unaffected by $\lambda_{t-1}$. As firms choose to price above the kink in Figure $1, \lambda^{*}<\lambda_{t-1}$. Moreover, as only the young are served, output equals $\lambda_{t}=\lambda^{*}$.

Lemma $3 \hat{\lambda}(\tilde{\lambda})>\tilde{\lambda}>\lambda^{*}$.

Proof: This can be seen by setting $\lambda_{t-1}$ in Figure 1 at $\tilde{\lambda}$ so that $\hat{\lambda}$ corresponds to $\hat{\lambda}(\tilde{\lambda})$. Now note that $\hat{\lambda}(\tilde{\lambda})>\tilde{\lambda}>\lambda^{*}$.

We can now depict the relationship between $\lambda_{t-1}$ and $\lambda_{t}$ as in Figure 3 . When $\lambda_{t-1}$ is zero, the market size is merely doubled so that pricing is the same as when $\lambda_{t-1}$ is unity, although output is doubled. Under Assumption 3(a) this makes $\lambda_{t}(0)=\lambda_{t}(1)$ as drawn in Figure 3. Under Assumption 3(b), $\lambda_{t}(0)>\lambda_{t}(1)$ since the higher aggregate profits at $\lambda_{t-1}=0$ shift demand up compared to when $\lambda_{t-1}=1$. This is the only difference between the two cases.

Proposition 2 The economy must have finite period cycles. If $G($.$) is uni-$ form, only two period cycles are possible. 
Figure 3: A Three Period Cycle

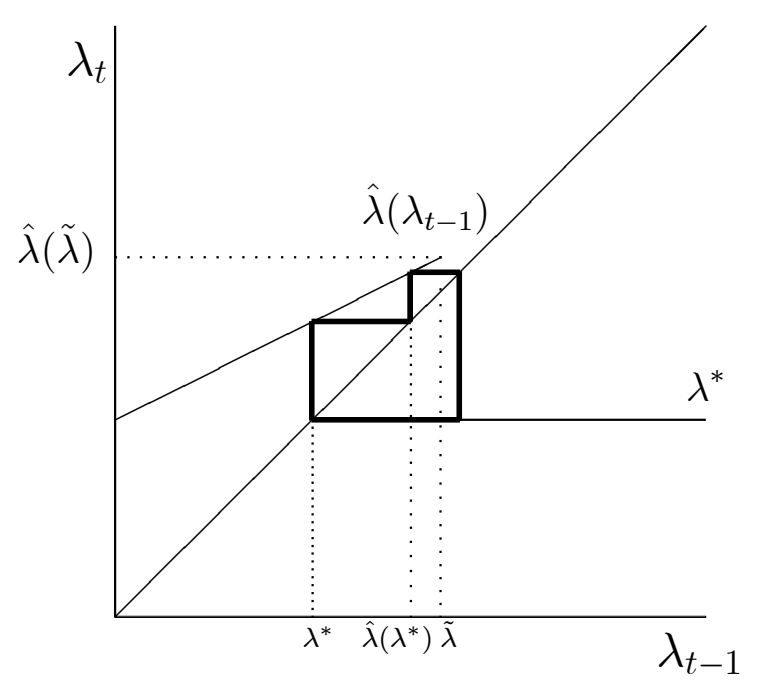

Proof: Let $m$ be the smallest horizontal difference between the $\hat{\lambda}($.$) curve and$ the $45^{0}$ line. Then for $\lambda_{t-1}<\tilde{\lambda}, \lambda_{t}-\lambda_{t-1}$ is at least $m$. Also note that $\lambda_{t-1}$ cannot fall below $\lambda^{*}$. Thus, $\lambda$ can rise for at most $\frac{\tilde{\lambda}-\lambda^{*}}{m}$ periods before falling back to $\lambda^{*}$. When $G($.$) is uniform, only two period cycles$ exist as $\hat{\lambda}\left(\lambda^{*}\right)>\tilde{\lambda}$ so that firms cycle between $\hat{\lambda}\left(\lambda^{*}\right)$ and $\lambda^{*}$ in this case. A proof is available on request.

Figure 3 depicts this progression in a three-period cycle.

\subsection{Some Empirical Implications}

Among the stylized facts on business cycles are pro-cyclical real wages, countercyclical prices and durable good consumption more volatile than output. There is much evidence in the empirical literature suggesting that wages rise with output, that is they are procyclical. Real wages, when measured appro- 
priately, tend to be pro-cyclical although some studies find that they are not tightly tied to the business cycle. Using longitudinal data, Barsky, Parker and Solon (1994) show that individual real wages are more pro-cyclical than average wages which are at best marginally procyclical. This is a consequence of marginal workers with below average wages entering the labor market in good times which drags average wages down. Using cross sectional data they also show that durable goods prices, as well as the prices of non durables in concentrated industries, are significantly counter-cyclical.

Nominal wages in our model are fixed in terms of the numeraire good. However, real incomes are not and the real incomes of different groups may move differently. We define real incomes as the income left over for the consumption the non durable good. Thus, individuals who purchase the good are better off as $\frac{\Pi_{t}}{2}-P_{t}$ rises. Those who do not buy the good gain if $\Pi_{t}$ rises. In the first period of the boom $\Pi_{t}-P_{t}$ rises as this is necessary for more of the young to be served. Profits also rise as firms prefer $\hat{\lambda}\left(\lambda^{*}\right)$ to $\lambda^{*}$ although the latter is still available to them. Later in the upturn, $\lambda$ rises and equilibrium profits fall (as the curve $\hat{\pi}$ shifts down) though $\Pi_{t}-P_{t}$ necessarily rises with $\lambda$. When the downturn comes, $\lambda$ falls, taking $\Pi_{t}-P_{t}$ with it. In addition profits fall to their minimum of $\Pi^{*}$. Figure 4 depicts the path of $\lambda_{t}, Q_{t}, \Pi_{t}$, and $\frac{\Pi_{t}}{2}-P_{t}$. Thus, correlation between $\frac{\Pi_{t}}{2}-P_{t}$, the real income of the rich, and profits need not be positive or negative, and our work supports the idea that disaggregated data, both across groups of individuals 
Figure 4: Empirical Implications
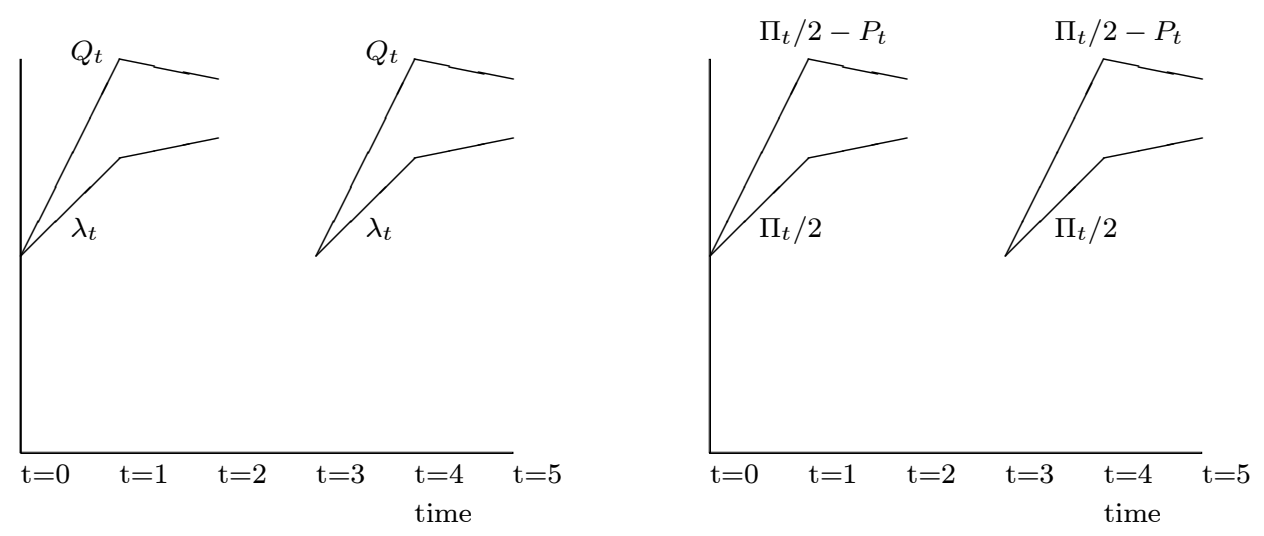

as well as over periods in the cycle need to be examined.

Stock and Watson (1999) report that the cyclical component of prices is counter-cyclical, and that this negative correlation is stable since the early 50s. There have been many explanations in the literature for the observed counter-cyclical prices and markups, especially in durable goods and with imperfectly competitive markets. Stiglitz (1984) argues that this occurs because marginal buyers have more elastic demand. Similarly, Bils (1989) argues that in booms, consumers with low willingness to pay enter the market and this raises demand elasticity, which causes price decreases in booms. Rotemberg and Saloner (1986) argue that counter cyclical pricing comes from enforcing collusion. The gains from price cutting are higher in good times so that only lower prices can be supported in a repeated game.

In our model there are two factors that determine income, and hence 
willingness to pay: profit earnings and wage income. Wage income is acyclical while profit earnings tend to rise with output. For output to rise a higher proportion of consumers need to be able to buy the durable good. Thus, the behavior of prices in our model depends on the distribution of profits. If profits are distributed evenly to all consumers, then income level in a boom will rise, and both prices and output could rise. If profits are captured by only a small group, then prices must fall for output to rise. Thus, unless asset ownership is widespread, the model's predictions accord with the facts.

Durable goods sales are widely understood to be pro-cyclical and more volatile than output. ${ }^{19}$ Durable good consumption rises in our model during good times and as total labor supply is fixed, consumption of non durables actually shrinks in a boom. This makes sales of durables more volatile than total output. Adding an elastic labor supply would allow non durables production to be procyclical as well.

\section{Asymmetric Equilibrium}

In the previous section we assumed all firms were symmetric. In this section we allow firms to inherit different market sizes and show that it does not affect our results.

Proposition 3 Even if firms differ in terms of their inherited market size, each firm has a finite period cycle and there are a finite number of firm types

\footnotetext{
${ }^{19}$ See, for example, Stock and Watson (1999), King and Rebelo (1999), and Cooley and Prescott (1995).
} 
in steady state. Hence, aggregate cycles are of finite length.

Proof: Firms, with different market sizes will have different $\pi\left(\Pi, \lambda_{t-1}\right)$ curves as a function of $\Pi$ alone. However, for the same reasons as earlier, these curves are increasing but flatter than the $45^{0}$ line, have positive intercepts and are convex. Under Assumption 3(b), each type will have different aggregate profit levels $\left(\tilde{\Pi}\left(\lambda_{t-1}\right)\right)$ at which their profit functions switch from being $\pi^{*}(\Pi)$ to $\hat{\pi}\left(\Pi, \lambda_{t-1}\right)$. To derive equilibrium profits, we need to construct the appropriate (according to the distribution of firm types) convex combination of these profit functions. However, this aggregate function will have the same properties, namely, it will be increasing but flatter than the $45^{0}$ line, have a positive $Y$ intercept and be convex in aggregate profits. The intersection of this aggregate profit function with the $45^{0}$ line gives unique aggregate profits in equilibrium. Under Assumption 3(a), profits do not affect demand so that the behavior of firms is independent of aggregate profit levels and hence of the distribution of firms. The analysis of the previous section carries over and asymmetries of this form do not affect the analysis. Firms who served $\lambda_{t-1}$ of the young in the previous period choose to serve $\hat{\lambda}\left(\lambda_{t-1}\right)$ of the young today if $\lambda_{t-1}<\tilde{\lambda}$, while if $\lambda_{t-1}>\tilde{\lambda}$, they serve $\lambda^{*}$ of the young. Since cycles for each firm are of finite length, so are the number of different types of firms in steady state.

Under Assumption 3(b), things are more complicated. As the distri- 
bution of firms changes, so does the level of equilibrium profits. For a given distribution of firms, and aggregate profits, some firms will choose to price at $\lambda^{*}(\Pi)$. Others will choose to price at different levels along $\hat{\lambda}\left(\Pi, \lambda_{t-1}\right)$. It can be verified by using Figure $1(b)$ that the $\hat{\lambda}($. and $\lambda^{*}($.$) curves shift upwards with an increase in aggregate profits.$ This follows from the fact that output and hence the proportion of young served rising with aggregate profits. $\tilde{\lambda}(\Pi)$ also rises with aggregate profits. Recall that the slope of individual profits in Figure 2 is related to the output chosen. Hence $\hat{\pi}_{\Pi}(\Pi, \tilde{\lambda})>\pi_{\Pi}^{*}(\Pi)$. Thus to keep $\hat{\pi}(\Pi, \tilde{\lambda})=\pi^{*}(\Pi), \lambda$ needs to rise with an increase in aggregate profits.

We know that in equilibrium, profits cannot be lower than those that obtained when all firms sell only to the young or higher than those when all firms served no consumer in the previous period, $\lambda_{t-1}=0$, that is they must lie between $\Pi^{*}$ and $\hat{\Pi}(0)$ derived in the symmetric case. For each profit level in the interval $\left[\Pi^{*}, \hat{\Pi}(0)\right]$ there is a $\hat{\lambda}\left(\Pi, \lambda_{t-1}\right)$ and a $\tilde{\lambda}(\Pi)$. Let $m^{\prime}(\Pi)>0$ be the smallest horizontal distance between $\hat{\lambda}\left(\Pi, \lambda_{t-1}\right)$ and the $45^{0}$ line, and let $m^{\prime}>0$ denote the smallest value of $m^{\prime}(\Pi)$ for all $\Pi$ in the interval $\left[\Pi^{*}, \hat{\Pi}(0)\right]$. Thus, a firm which inherits a $\lambda_{t-1}$ below $\tilde{\lambda}($.$) must increase its \lambda$ by at least $m^{\prime} . \tilde{\lambda}(\hat{\Pi}(0))$ is the highest value of $\tilde{\lambda}($.$) that is possible and \lambda^{*}\left(\Pi^{*}\right)$ is the lowest value that $\lambda$ can take. Hence a firm can take at most $\frac{\tilde{\lambda}(\hat{\Pi}(0))-\lambda^{*}\left(\Pi^{*}\right)}{m^{\prime}}$ periods to cross the switchover point. Hence, each firm can have at most a 
cycle of length $\frac{\tilde{\lambda}(\hat{\Pi}(0))-\lambda^{*}\left(\Pi^{*}\right)}{m^{\prime}}$. As a consequence, there can be at most $\frac{\tilde{\lambda}(\hat{\Pi}(0))-\lambda^{*}\left(\Pi^{*}\right)}{m^{\prime}}$ different kinds of firms since when a firm switches over, it joins all other firms which have switched with it.

\subsection{No Aggregate Cycles}

Although we have shown that individual firms must have cycles, there need not be aggregate cycles, although this is a non-generic case. Suppose that half the firms inherit $\lambda^{*}\left(\Pi^{\prime}\right)$ while the other half inherit $\hat{\lambda}\left(\lambda^{*}, \Pi^{\prime}\right)$ and aggregate profits, $\Pi^{\prime}$, are such that the profit function derived by giving equal weight to these two types of firms intersects the $45^{0}$ line at $\Pi^{\prime}$ so that this is an equilibrium. Let $\hat{\lambda}\left(\lambda^{*}, \Pi^{\prime}\right)>\tilde{\lambda}\left(\Pi^{\prime}\right)$ as is the case with the uniform distribution. Given this level of profits, firms which inherit $\lambda^{*}\left(\Pi^{\prime}\right)$ choose to serve both the young and old and serve $\hat{\lambda}\left(\lambda^{*}, \Pi^{\prime}\right)$ of their young, while firms which inherit $\hat{\lambda}\left(\lambda^{*}, \Pi^{\prime}\right)$ choose to serve only their young, and $\lambda^{*}\left(\Pi^{\prime}\right)$ of them. In each period, firms switch types so that there are no aggregate cycles. ${ }^{20}$ Similarly, there are no aggregate cycles if there are $T$ types of firms, each with a proportion $1 / T$, and with $T$ period cycles. In this case, firms switch types but the distribution of types is unchanged over time.

\subsection{Aggregate Cycles}

When aggregate market size varies over time, the economy has aggregate cycles. The depth of the cycle depends on the asymmetry between firms.

\footnotetext{
${ }^{20}$ This argument is valid under both Assumption 3(a) and 3(b).
} 
Figure 5: Two Period Cycles

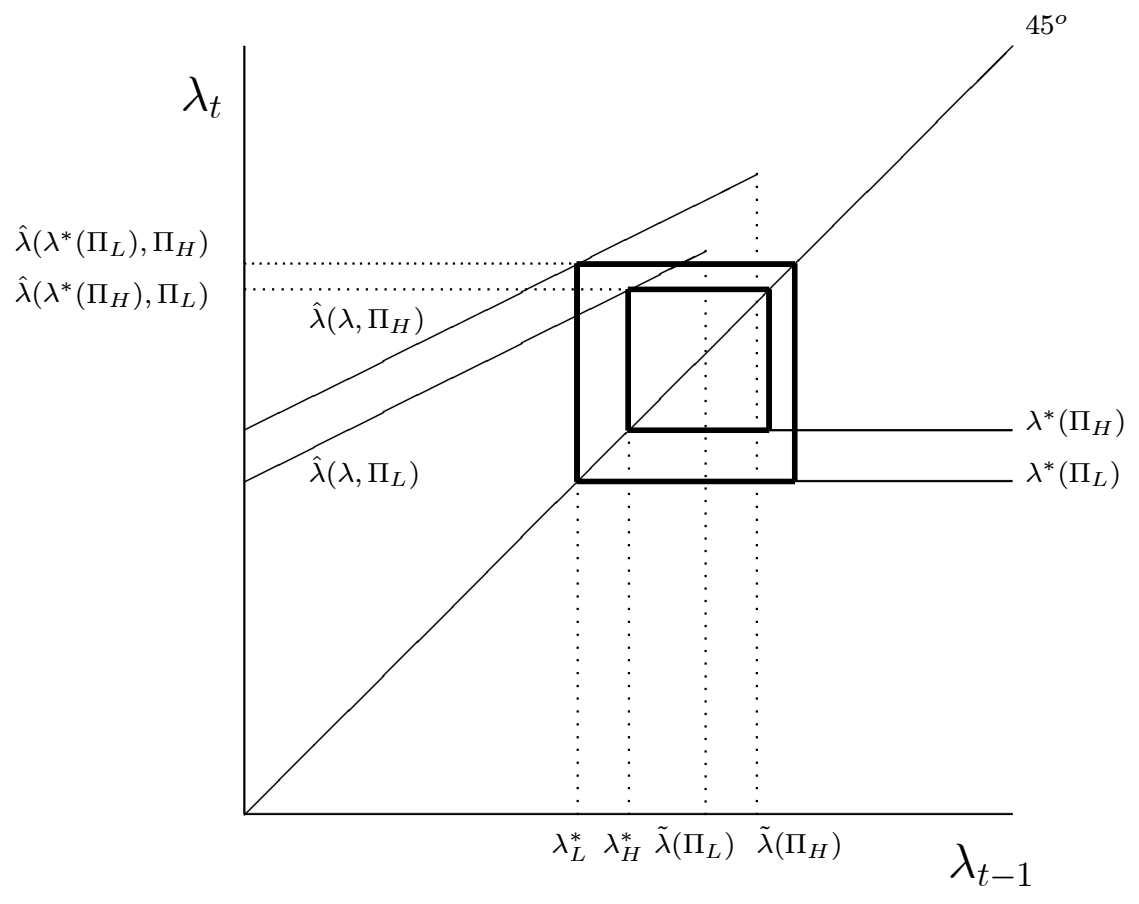

Figure 5 depicts a two period aggregate cycle under Assumption 3(b). In this case there are at most two types of firms. Those types which have a large market in the current period and those who have a smaller market. If there are a greater proportion of the first type, aggregate profits are higher than when the reverse is true. Call the equilibrium profits in the first instance $\Pi_{H}$ and in the second $\Pi_{L}$. Firms of the first type whose good periods are synchronized with that of the market, cycle between $\hat{\lambda}\left(\lambda^{*}\left(\Pi_{L}\right), \Pi_{H}\right)$ and $\lambda^{*}\left(\Pi_{L}\right)$ (denoted by $\lambda_{L}^{*}$ ) while firms of the second type whose good periods, are asynchronized with the market, cycle between $\hat{\lambda}\left(\lambda^{*}\left(\Pi_{H}\right), \Pi_{L}\right)$ and $\lambda^{*}\left(\Pi_{H}\right)$ (denoted by $\lambda_{H}^{*}$ ). Note that an increase in aggregate profits shifts $\hat{\lambda}(., \Pi)$, 
$\lambda^{*}(\Pi)$ and $\tilde{\lambda}(\Pi)$ upwards. This two period cycle will be the case if

$$
\hat{\lambda}\left(\lambda^{*}\left(\Pi_{L}\right), \Pi_{H}\right)>\hat{\lambda}\left(\lambda^{*}\left(\Pi_{H}\right), \Pi_{L}\right)>\tilde{\lambda}\left(\Pi_{H}\right)>\tilde{\lambda}\left(\Pi_{L}\right)>\lambda^{*}\left(\Pi_{H}\right)>\lambda^{*}\left(\Pi_{L}\right) .
$$

In this event, the cycle of type 1 firms encloses the cycle of type 2 firms. Thus, their cycle is deeper than that of type 2 firms as depicted.

Under Assumption 3(a), there are no aggregate profit effects so that the $\hat{\lambda}(\lambda)$ and $\lambda^{*}$ curves are independent of the aggregate profit level in equilibrium. In this case, all firms follow the same path. Yet, there is an aggregate cycle if the proportion of firms are not equal. There can be aggregate cycles

of more than two period length in steady state if $\hat{\lambda}\left(\lambda^{*}\right)<\tilde{\lambda}$. However, cycles remain of finite length since there are a finite number of type of firms, each with a cycle of finite length.

\subsection{Income Distribution and the Cycle Depth}

Under Assumption 3(a), distribution of ownership shares and hence profits is very unequal while it is equal under Assumption 3(b). A comparison of the outcomes under these two assumptions gives some insight into how the distribution of assets might affect the depth of cycles. Consider a two period aggregate cycle case. Let $\sigma \geq 1 / 2$ denote the proportion of firms that are in the majority. As this majority rises, profits in the good state $(H)$ and bad state $(L)$ diverge, i.e., cycles deepen. When $\sigma$ equals unity, all firms are alike so that aggregate profits in the good state are as high as they will 
Figure 6: The Depth of the Cycle

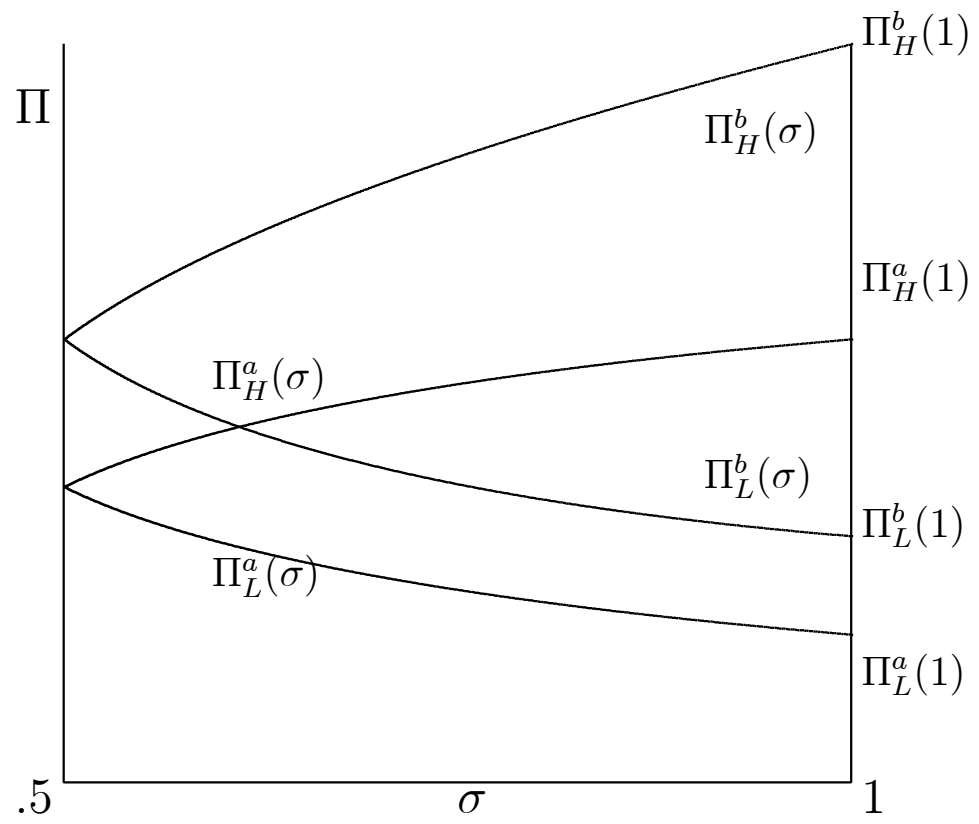

get and in the bad state are as low as they will get. ${ }^{21}$ When $\sigma$ equals one half, then there are no aggregate cycles. Figure 6 depicts this relationship under assumptions $3(a)$ and $3(b)$ respectively. When profits are distributed evenly, the level of profits in both states is higher than when profits accrue only to the most productive (Assumption 3(b) versus 3(a)). The difference in the good and bad states is also greater so that the two curves are more spread out as drawn. This suggests that an economy with a more widespread ownership of productive assets would also be faced with deeper cycles! $!^{22}$

\footnotetext{
${ }^{21}$ In the bad period $\Pi_{L}(1)=\Pi^{*}$, and in the good period $\Pi_{H}(1)=\hat{\Pi}\left(\lambda^{*}\right)$.

${ }^{22}$ More generally, when more assets are held by the more productive, a boom will raise profits and make the demand curve more inelastic as well as shifting it upwards. By assuming an equal distribution of assets, we have eliminated the first effect which would tend to reduce output and raise price in a boom.
} 


\section{Robustness}

In this section we show that relaxing a number of assumptions made so far, including that of myopic behavior on the part of firms, and no credit markets will not change our main results.

\subsection{Forward Looking Behavior}

We have assumed so far that firms maximize their current period profits. They do not take the effects of their current choice on future profits into account. Here we look at the effect of such forward looking behavior on the part of firms and argue that such behavior tends to deepen the cycle, not eliminate it. ${ }^{23}$

Think of a firm as choosing not output or price, but equivalently the proportion of young consumers it serves, $\lambda_{t}$. By reducing $\lambda_{t}$ today, a firm can increase its market size tomorrow. We need to add the value of future which depends only on its choice of $\lambda_{t}$, denoted by $Z\left(\lambda_{t}\right)$, to the objective function of a firm. Thus, a forward looking firm maximizes

$$
\pi\left(\lambda_{t}, \lambda_{t-1}, \Pi_{t}\right)+Z\left(\lambda_{t}\right)
$$

and chooses $\lambda_{t}$ so that

$$
\pi_{\lambda_{t}}\left(\lambda_{t}, \lambda_{t-1}, \Pi_{t}\right)+Z_{\lambda_{t}}\left(\lambda_{t}\right)=0 .
$$

\footnotetext{
${ }^{23}$ Nor for that matter, would the possibility of carrying inventories affect our results as production costs are constant so that there is no gain from carrying inventories, and if there are any costs of doing so, there will be no incentives to carry inventories.
} 
On the other hand, a myopic firm maximizes $\pi\left(\lambda_{t}, \lambda_{t-1}, \Pi_{t}\right)$, and chooses $\lambda_{t}$ so that

$$
\pi_{\lambda_{t}}\left(\lambda_{t}, \lambda_{t-1}, \Pi_{t}\right)=0
$$

Since serving a greater proportion of the young today reduces the firm's demand and hence profits tomorrow, $Z_{\lambda_{t}}\left(\lambda_{t}\right) \leq 0$. Hence, a forward looking firm will, if anything, want to hoard customers. ${ }^{24}$

Consider the symmetric firm case with two period aggregate cycles. How would a forward looking firm's choices differ from those of a myopic one? In good times, when profits are high, a firm has no incentive to reduce $\lambda_{t}$ since it will not serve the customers it has hoarded in the next, low aggregate profit period, anyway. In other words, in good times $Z_{\lambda_{t}}\left(\lambda_{t}\right)=0$, and a forward looking firm chooses the same level of output as a myopic firm. However, in bad times, since it will serve its hoarded customers in the next period, i.e., since $Z_{\lambda_{t}}\left(\lambda_{t}\right)<0$, a firm will have an incentive to reduce $\lambda_{t}$ below that of a myopic firm. ${ }^{25}$ But this will just deepen the cycle! ${ }^{26}$

\footnotetext{
${ }^{24}$ Although profits are not single peaked there is an interior maximum so that the first order conditions hold.at every local maximum.

${ }^{25}$ Note that profits fall as $\lambda_{t}$ rises up till $\tilde{\lambda}$, and then are flat. Due to this, profits are weakly decreasing and convex in $\lambda_{t}$. As a result of this convexity in profits, a firm tends to like variability in $\lambda_{t}$.

${ }^{26} \mathrm{It}$ is also worth pointing out that allowing for some competition between firms will weaken the incentive to hoard customers as hoarded customers are like a public good, available to all competitors of the firm as well as itself.
} 


\subsection{Credit Markets}

So far we have assumed that there are no credit markets, or for that matter, even savings possibilities, available to the consumer. We now argue that our results are not dependent on this assumption. Credit markets reduce the distortion caused by indivisibilities by increasing the set of consumers who can afford to buy the good. However, cycles remain.

We assume that credit markets are perfect and all those who can repay their loans have access to credit. We show that while credit markets improve welfare by expanding the range of consumers who can afford the durable, they do not eliminate cycles. For simplicity, we only use Assumption 3(a) in this section. The results can be generalized at the cost of some complexity. We will proceed as follows. First we will outline how the availability of credit affects effective demand. From this we derive the demand and supply of credit and show that when the rate of time preference, $\rho$, is zero, the analysis looks no different from that above.

The availability of credit changes the effective demand faced by the monopolist. When the price is $P_{0}$, and only the young are served, individuals with productivity exceeding $P_{0}$ can buy the good even in the absence of credit markets. However, credit allows more individuals to afford the good, ceteris paribus. Without credit markets, the demand by the young was given by the line $A B$ in Figure 7. With credit markets, an individual can afford the good if the price is less than the present discounted value of his income, $P \leq \frac{2+r}{1+r} \gamma$. 
Figure 7: Credit Supply and Demand

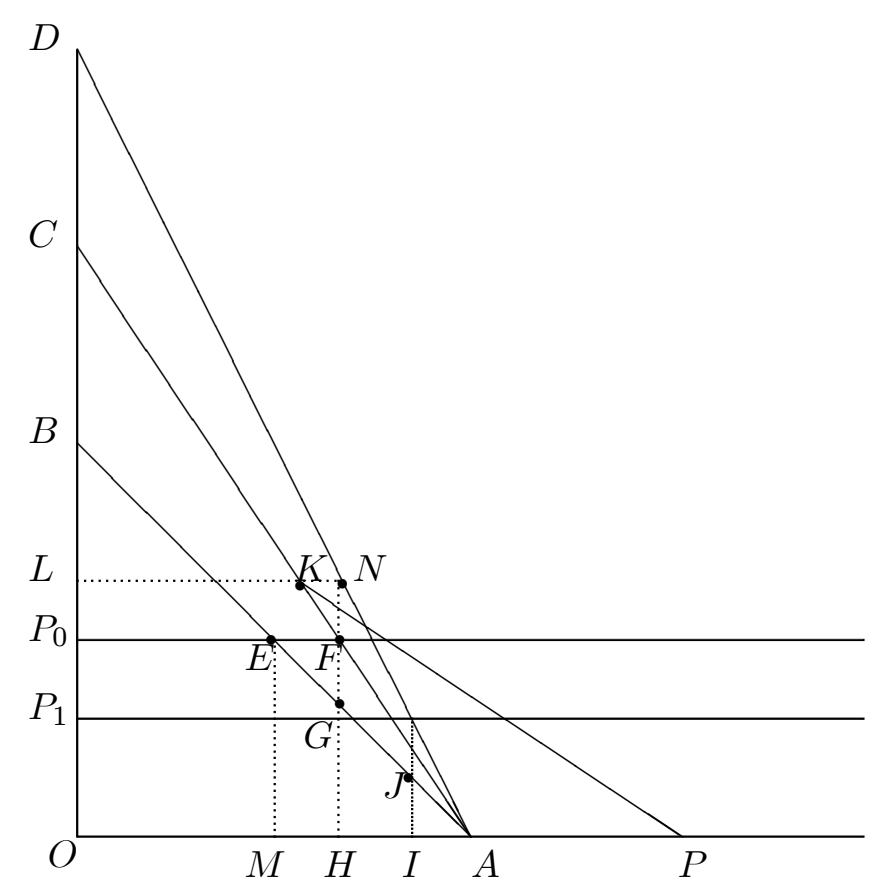


Thus, demand by the young consumers shifts up to $A C$ where the point $C$ corresponds to the coordinates $\left(0, \frac{2+r}{1+r}\right)$.

Credit markets also affect demand by the old consumers. Individuals who lent money when they were young have an income equal to $(2+r)$ times their productivity in their second period. This relation is represented by the line $A D$ where $D$ corresponds to the coordinates $(0,2+r)$ in Figure 7 . This line lies above $A C$ for $r>0$. Suppose the price in the last period was $P_{0}$. Individuals to the right of $H$ were unable to buy the good in the last period and their willingness to pay today lies along the line $N A$. Thus their demand is given by $N A$, taking $H$ as the origin. If price exceeds $L$, then none of the old can afford to buy the good. Only for prices below $L$ can the old participate. Thus, total demand from the young and the old in period 1 is the horizontal sum of the demand of the young and old, and this results in the kinked demand curve, $C K P$.

The equilibrium interest rate, $r$, is such that demand for credit is equal to the supply of credit. What are the demand for and supply of credit at given levels of prices? First note that only the young participate in the credit market. The old earn revenue from repayments of past loans but neither lend nor borrow. Now, suppose that only the young are served in period 0 while both young and old are served in period 1 . Let $P_{0}$ be the price in period 0 . Then, individuals in $M H$ demand credit as they can afford the good on the basis of their net worth but not based on their current income. Their demand 
for credit is the difference between $P_{0}$ and their current income. Hence credit demand is given by the area $E F G$. As $r$ rises $A C$ becomes flatter and at given prices demand for credit falls. Hence we have the usual downward sloping demand for credit.

The supply of credit comes from two sources. The first source is individuals who cannot afford the good today, even if they borrow, but who could afford it tomorrow if they save today and lend. If the price in period 1 is given by $P_{1}$, this consists of the individuals in the region $H I$ in Figure 7 whose supply of credit is the area $H G J I$. The second source is individuals whose income exceeds the price of the durable, that is, those in region $O M$ who supply credit equal to the area $P_{0} B E+\frac{\Pi}{2}$ (since profits are captured by some of these agents), as well as individuals whose lifetime income (in present value terms) is not high enough to afford the durable good even if they postpone consumption to the second period. This consists of individuals in the region $I A$ who supply credit equal to area $I J A$. The first source is willing to lend (but only what is needed to buy the durable in the next period) even if the interest rate, $r$, is less than the rate of time preference, $\rho$, as lending today enables them to transfer part of their income to tomorrow and thus afford to buy the durable in their second period. On the other hand, the second source is willing to lend only if $r \geq \rho$ because their motive in lending is to consume more of the non durable good later on.

If $r<\rho$, the only source of credit is the first one and as $r$ rises $A D$ 
swings out and $A C$ swings in moving $I$ to the right and $H$ to the left thereby increasing credit supplied. If $r>\rho$, all agents to the right of $H$ and left of $M$ supply credit. Since an increase in $r$ moves $H$ to the left and leaves $M$ unchanged, credit supplied rises as $r$ rises. At $r=\rho$, there is a flat part for credit supply corresponding to individuals in $O M$ and $I A$ becoming just willing to supply credit here. This flat segment makes $r=\rho$ a likely candidate to be the equilibrium interest rate. Suppose $\rho=0$. In this event, it can be verified that $r=\rho=0$ is the unique equilibrium interest rate under assumption $3(a)$ and a uniform distribution of $\gamma \cdot{ }^{27}$

This case when $r=\rho=0$ is illustrated in Figure 8. Note that here the curves $A C$ and $A D$ are identical. If the monopolist serves only the young he maximizes profits choosing $E$ along $A D$. In the subsequent period, demand is given by $D E F$ as the kink occurs at $E$ (the last period's price) as in the original model without credit. The monopolist chooses the point $G$ to maximize profits and prices at $P_{1}<P_{0}$. Of course, this results in a kink in the subsequent period at $H$, so that demand is given by $D H I$. The monopolist now finds it optimal to price at $E$ and so the cycle develops. Note that the only difference between this analysis and that without credit is that $A D$ plays the role of $A B$ earlier. For the same reasons as before, we must have cycles. For small perturbations in $r$ and $\rho$, similar arguments work.

\footnotetext{
${ }^{27}$ In the uniform distribution case it is easy to show that if $\rho=0$, there are only two period cycles and $r=0$ is the only equilibrium in both periods of the cycle. The proof is in the Appendix.
} 
Figure 8: Credit Supply and Demand

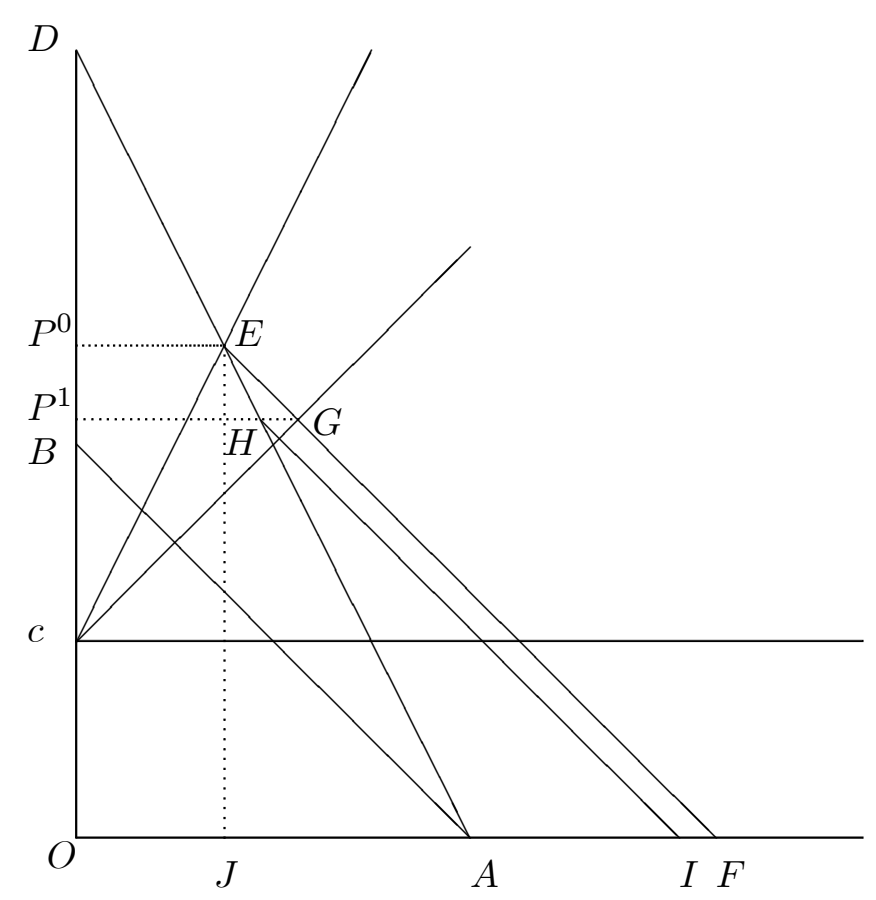




\section{Concluding Remarks}

Our work in this paper suggests an important role for income distribution, and for the distribution of asset ownership on the characteristics of cycles that economy will experience. It also provides a way of looking at the effects of inside as done above, and outside credit on the economy. In addition, the simple general equilibrium structure developed provides a way to study a number of issues in trade and development which are the subject of ongoing research.

\section{References}

[1] Barsky, Robert, J. Parker and Gary Solon (1994). "Measuring the Cyclicality of Real Wages: How Important is the Composition Bias?" Quarterly Journal of Economics, Vol. 109(1), pp. 1-25.

[2] Bils, Mark (1987). "The Cyclical Behavior of Marginal Cost and Price," American Economic Review, 77(5), December, pp. 838-855.

[3] Bils, Mark (1989). "Cyclical Pricing of Durable Goods," NBER Working Paper 3050, July, 1989.

[4] Bulow, Jeremy (1982). "Durable Goods Monopolists," Journal of Political Economy, Vol. 90(2), 314-333. 
[5] Caplin, Andrew (1985). "The Variability of Aggregate Demand with (S,s) Inventory Policies," Econometrica, 53(6), November, pp. 13951410.

[6] Conlisk, John, Eitan Gerstner and Joel Sobel (1984). "Cyclic Pricing by a Durable Goods Monopolist," Quarterly Journal of Economics, 99(3), August, pp. 489-505.

[7] Cooley, Thomas F. and Edward C. Prescott (1995). "Economic Growth and Business Cycles." In Frontiers of Business Cycle Research, Thomas Cooley (ed.), Princeton University Press.

[8] Diamond, Peter and Drew Fudenberg (1989). "Rational Expectations Business Cycles in Search Equilibrium," Journal of Political Economy, $97(3)$, pp. 606-619.

[9] Gordon, Robert J. (1980). "Post War Macroeconomics: The Evolution of Events and Ideas." In The American Economy in Transition, Martin Feldstein (ed.), University of Chicago Press.

[10] Grandmont, Jean-Michel (1985). "On Endogenous Competitive Business Cycles," Econometrica, 53(5), September, pp. 995-1045.

[11] Howitt, Peter and Preston McAfee (1992). "Animal Spirits," American Economic Review, 82(3), June, 493-507. 
[12] King, Robert G. and Sergio Rebelo (2000). "Resuscitating Real Business Cycle Models." In Handbook of Macroeconomics, Volume 1B, Chapter 14, Michael Woodford and John Taylor (eds.), North Holland.

[13] Krishna, Kala and Cemile Yavas (2000). "Some Implications of Wage Equality in a General Equilibrium Model with Indivisibilities." Available at http://papers.ssrn.com.

[14] Ng, Y.K. (1965). "Why do People Buy Lottery Tickets? Choices Involving Risk and the Indivisibility of Expenditure," Journal of Political Economy, 73(5), pp. 530-535.

[15] Olney, Martha (1999). "Avoiding Default: The Role of Credit in the Consumption Collapse of 1930," Quarterly Journal of Economics, CXIV, February, pp. 319-335.

[16] Rogerson, Richard (1988). "Indivisible Labor, Lotteries and Equilibrium," Journal of Monetary Economics, 21(1), January, pp. 3-16.

[17] Rotemberg, Julio J. and Garth Saloner (1986). "A Supergame Theoretic Model of Price Wars during Booms," American Economic Review, 76(3), June, pp. 390-407.

[18] Scarf, Herbert (1981a). "Production Sets with Indivisibilities, Part I: Generalities," Econometrica, 49(1), January, pp. 1-32. 
[19] Scarf, Herbert (1981b). "Production Sets with Indivisibilities, Part II: The Case of Two Activities," Econometrica, 49(2), March, pp. 395-423.

[20] Shleifer, Andrei (1986). "Implementation Cycles," Journal of Political Economy, 94(6), pp. 1163-1190.

[21] Stiglitz, Joseph E. (1984). "Price Rigidities and Market Structure," American Economic Review, 74(3), June, pp. 433-444.

[22] Stock, James H. and Mark W. Watson (1999). "Business Cycle Fluctuations in U.S. Macroeconomic Time Series." In Handbook of Macroeconomics, Volume 1A, Chapter 1, Michael Woodford and John Taylor (eds.), North Holland.

[23] Stokey, Nancy L. (1979). "Intertemporal Price Discrimination," Quarterly Journal of Economics, August, pp. 355-371. 


\section{A Appendix}

\section{A.1 Calculations for the Uniform Distribution Case}

In this Appendix we show that cycles are two period ones when the productivity parameter is distributed uniformly, $\gamma^{\sim} U[0,1]$, even if firms are not symmetric. Recall that when firms were symmetric, then two period cycles were ensured if $\hat{\lambda}\left(\lambda^{*}\right)>\tilde{\lambda}$ as shown in Section 3. When firms are not symmetric, then the distribution of young served across firms affects the equilibrium level of profits as argued in Section 4. As a result, corresponding to any given distribution and hence aggregate profit level in equilibrium, there correspond functions $\hat{\lambda}\left(\lambda^{*}, \Pi\right), \lambda^{*}(\Pi)$ and $\tilde{\lambda}(\Pi)$ each of which has been shown to be increasing in $\Pi$ as depicted in Figure 5.

A sufficient condition for each firm to have only two period cycles is thus that for each level of aggregate profits, and each viable value of $\lambda^{*}$, $\hat{\lambda}\left(\lambda^{*}, \Pi\right)>\tilde{\lambda}(\Pi)$. Recall that $\hat{\lambda}(\lambda, \Pi)$ increases as $\lambda$ or $\Pi$ rise and $\tilde{\lambda}(\Pi)$ rises with $\Pi$. Thus, if the above holds at the lowest feasible value of $\lambda^{*}$ and $\Pi$ on the left hand side and the highest possible value of $\Pi$ on the right hand side then it must hold throughout. The lowest feasible value of $\lambda$ is the value of $\lambda^{*}$ for the lowest feasible value of aggregate profits. The lowest level of equilibrium profits occurs when none of the old are served by anyone. This results in aggregate profits of $\Pi^{*}$. When all firms inherit the largest feasible market, i.e., the share of young served in the last period takes its lowest 
value, the highest feasible value of $\Pi=\hat{\Pi}\left(\lambda^{*}\right)$ is realized. Thus,

$$
\hat{\lambda}\left(\lambda^{*}\left(\Pi^{*}\right), \Pi^{*}\right)>\tilde{\lambda}\left(\hat{\Pi}\left(\lambda^{*}\left(\Pi^{*}\right)\right)\right.
$$

is sufficent to ensure that there are only two period cycles, even with asymmetric firms.

We first find $\lambda^{*}$ and $\Pi^{*}$. The profit level associated with the demand curve $D^{*}, \pi^{*}(\Pi)$, is the value function for the problem:

$$
\underset{P}{\operatorname{Max}}\left(1+\frac{\Pi}{2}-P\right)(P-c)
$$

The optimal price and quantity when aggregate profits are $\Pi^{*}$ are

$$
\begin{aligned}
P^{*} & =\frac{1}{2}\left(1+\frac{\Pi}{2}+c\right) \\
q^{*} & =\frac{1}{2}\left(1+\frac{\Pi}{2}-c\right) .
\end{aligned}
$$

Output is also equal to $\lambda^{*}(\Pi)$ as no old consumers are served. Individual firm's profits are

$$
\pi^{*}=\frac{1}{4}\left(1+\frac{\Pi}{2}-c\right)^{2}
$$

Of course, $\Pi^{*}$, can be solved for by setting firm profits equal to aggregate levels or implicitly from

$$
\Pi^{*}=\frac{1}{4}\left(1+\frac{\Pi^{*}}{2}-c\right)^{2}
$$

Now to find $\hat{\Pi}\left(\lambda^{*}\left(\Pi^{*}\right)\right)$. When all firms inherit $\lambda^{*}\left(\Pi^{*}\right)$, demand will have a kink at $q=\lambda^{*}\left(\Pi^{*}\right)$. The total number of potential consumers is $2-\lambda^{*}\left(\Pi^{*}\right)$ 
of which $1-\lambda^{*}\left(\Pi^{*}\right)$ are old consumers. Thus, the flatter part of the demand function can be expressed as

$$
\hat{D}=2-\lambda^{*}\left(\Pi^{*}\right)-2\left(P-\frac{\Pi}{2}\right) .
$$

The profit level associated with the demand curve $\hat{D}, \hat{\pi}\left(\Pi, \lambda^{*}\left(\Pi^{*}\right)\right)$, is the value function for the problem:

$$
\underset{P}{\operatorname{Max}}(P-c)\left(2-\lambda^{*}\left(\Pi^{*}\right)-2 P+\Pi\right)
$$

The optimal price level is

$$
\begin{aligned}
\hat{P}\left(\lambda^{*}\left(\Pi^{*}\right), \Pi\right) & =\frac{1}{4}\left(2-\lambda^{*}\left(\Pi^{*}\right)+2 c+\Pi\right) \\
& =\frac{3}{8}+\frac{5}{8} c+\frac{1}{4} \Pi-\frac{1}{16} \Pi^{*}
\end{aligned}
$$

when we substitute for $\lambda^{*}\left(\Pi^{*}\right)=q^{*}=\frac{1}{2}\left(1+\frac{\Pi^{*}}{2}-c\right)$. The resulting profit level is

$$
\begin{aligned}
\hat{\pi}\left(\Pi, \lambda^{*}\left(\Pi^{*}\right)\right) & =\left(\hat{P}\left(\lambda^{*}\left(\Pi^{*}\right), \Pi\right)-c\right)\left(2-\lambda^{*}\left(\Pi^{*}\right)-2 \hat{P}\left(\lambda^{*}\left(\Pi^{*}\right), \Pi\right)+\Pi\right) \\
& =2(\hat{P}-c)^{2} \\
& =\frac{1}{128}\left(6-\Pi^{*}-6 c+4 \Pi\right)^{2}
\end{aligned}
$$

using (4) to substitute for $2-\lambda^{*}\left(\Pi^{*}\right)+\Pi=4 \hat{P}\left(\lambda^{*}\left(\Pi^{*}\right), \Pi\right)-2 c$.

Demand by the young is represented by the steeper part of the demand curve, $D^{*}($.$) . The proportion of the young served, \hat{\lambda}\left(\lambda^{*}\left(\Pi^{*}\right)\right)$ can be found by going back to $D^{*}($.$) at \hat{P}\left(\lambda^{*}\left(\Pi^{*}\right), \Pi\right)$. Thus, $\hat{\lambda}\left(\lambda^{*}\left(\Pi^{*}\right), \Pi\right)$ is

$$
\begin{aligned}
\hat{\lambda}\left(\lambda^{*}\left(\Pi^{*}\right), \Pi\right) & =1+\frac{\Pi}{2}-\hat{P}\left(\lambda^{*}\left(\Pi^{*}\right), \Pi\right) \\
& =\frac{5}{8}(1-c)+\frac{\Pi}{4}+\frac{\Pi^{*}}{16}
\end{aligned}
$$


and at $\Pi=\Pi^{*}$

$$
\hat{\lambda}\left(\lambda^{*}\left(\Pi^{*}\right), \Pi^{*}\right)=\frac{5}{8}(1-c)+\frac{5}{16} \Pi^{*} .
$$

We now have the left hand side of (1) and turn to the right hand side. $\hat{\Pi}\left(\lambda^{*}\left(\Pi^{*}\right)\right)$ denotes the equilibrium level of aggregate profits when all firms inherit $\lambda^{*}\left(\Pi^{*}\right)$. Using (5) and setting individual profits to equal aggregate ones gives $\hat{\Pi}\left(\lambda^{*}\left(\Pi^{*}\right)\right.$ to be

$$
\hat{\Pi}\left(\lambda^{*}\left(\Pi^{*}\right)\right)=\frac{1}{128}\left(6-\Pi^{*}-6 c+4 \hat{\Pi}\left(\lambda^{*}\left(\Pi^{*}\right)\right)\right)^{2} .
$$

Now to find $\tilde{\lambda}\left(\hat{\Pi}\left(\lambda^{*}\left(\Pi^{*}\right)\right)\right)$. If aggregate profits are $\Pi$, then $\tilde{\lambda}(\Pi)$ can be found implicitly by setting

$$
\hat{\pi}(\Pi, \tilde{\lambda}(\Pi))=\pi^{*}(\Pi)
$$

Substituting for the two sides in the above using (5) and (2) gives

$$
\begin{aligned}
(\hat{P}(\tilde{\lambda}(\Pi), \Pi)-c)(2-\tilde{\lambda}(\Pi)-2 \hat{P}(\tilde{\lambda}(\Pi), \Pi)+\Pi) & =\frac{1}{4}\left(1+\frac{\Pi}{2}-c\right)^{2} \\
2-\tilde{\lambda}(\Pi)-2 c+\Pi & =\sqrt{2}\left(1+\frac{\Pi}{2}-c\right) \\
\tilde{\lambda}(\Pi) & =(2-\sqrt{2})\left(1-c+\frac{\Pi}{2}\right) .
\end{aligned}
$$

Evaluating $\tilde{\lambda}(\Pi)$ at $\hat{\Pi}\left(\lambda^{*}\left(\Pi^{*}\right)\right)$ gives the needed expression to be

$$
\tilde{\lambda}\left(\hat{\Pi}\left(\lambda^{*}\left(\Pi^{*}\right)\right)\right)=(2-\sqrt{2})\left(1-c+\frac{\hat{\Pi}\left(\lambda^{*}\left(\Pi^{*}\right)\right)}{2}\right) .
$$

Solving (3) and (8) gives the highest and lowest aggregate profit levels to 
$\mathrm{be}^{28}$

$$
\begin{aligned}
\Pi^{*} & =6+2 c-4 \sqrt{2+2 c} \\
\hat{\Pi}\left(\lambda^{*}\left(\Pi^{*}\right)\right) & =4+2 c-\sqrt{2+2 c}-2 \sqrt{4+4 c-2 \sqrt{2+2 c}}
\end{aligned}
$$

Substituting for $\Pi^{*}$ and $\hat{\Pi}\left(\lambda^{*}\left(\Pi^{*}\right)\right)$ as above in (7) and (9) gives

$$
\begin{aligned}
\hat{\lambda}\left(\lambda^{*}\left(\Pi^{*}\right), \Pi^{*}\right) & =\frac{5}{8}\left(1-c+\frac{\Pi^{*}}{2}\right) \\
& =\frac{5}{4}(2-\sqrt{2+2 c})
\end{aligned}
$$

and

$$
\begin{aligned}
\tilde{\lambda}\left(\hat{\Pi}\left(\lambda^{*}\left(\Pi^{*}\right)\right)\right) & =(2-\sqrt{2})\left(1-c+\frac{\hat{\Pi}\left(\lambda^{*}\left(\Pi^{*}\right)\right)}{2}\right) \\
& =(2-\sqrt{2})\left(3-\frac{1}{2} \sqrt{2+2 c}-\sqrt{4+4 c-2 \sqrt{2+2 c}}\right)(11
\end{aligned}
$$

Plotting the difference between the two using (10) and (11) and MAPLE shows that $\hat{\lambda}\left(\lambda^{*}\left(\Pi^{*}\right), \Pi^{*}\right)>\tilde{\lambda}\left(\hat{\Pi}\left(\lambda^{*}\left(\Pi^{*}\right)\right)\right)$ for all $c \in[0,1]$ which concludes the proof.

\section{A.2 Equilibrium When $r=\rho=0$}

We show that if $\rho=0$, then $r=0$ is the only equilibrium in both periods of the cycle when the productivity parameter is uniformly distributed in the unit interval.

\footnotetext{
${ }^{28}$ While there are two roots to the equations we choose the negative root as the positive ones results in infeasibly large output levels.
} 
Following the notation in Section 5.2 we call the period where firms serve only their young as period 0 , and therefore $P_{0}$ denotes the high price. Now, we first find this price, $P_{0}$, and calculate the demand for credit and supply of credit at $P_{0}$ if $r=\rho=0$. We find that supply exceeds credit in such a case. Even though potential supply exceeds demand at $r=0$, the entire supply comes from individuals who are indifferent between supplying credit and not, and supply of credit falls to zero at a negative interest rate. Therefore $r=0$ is the equilibrium interest rate. Next we show that in the following period, period $1, r=0$ remains the equilibrium interest rate.

\section{A.2.1 Period 0 : High Price Period}

The demand by the young at an interest rate of $r=0, D A$ in Figure 9, can be expressed as

$$
D^{*}(r=0)=1-\frac{P_{0}}{2}
$$

If the firm serves only its young consumers then the optimal price is a solution to the problem

$$
\underset{P_{0}}{\operatorname{Max}}\left(1-\frac{P_{0}}{2}\right)\left(P_{0}-c\right)
$$

which results in

$$
\begin{aligned}
& P_{0}=1+\frac{c}{2}, \text { and } \\
& q_{0}=\frac{1}{2}-\frac{c}{4}=\lambda_{0}
\end{aligned}
$$

Note that price exceeds 1 so that given Assumption 3(a) only the infinitesimally few who appropriate the profits can afford the good on their 
Figure 9: $\mathrm{r}=\rho=0$ Equilibrium
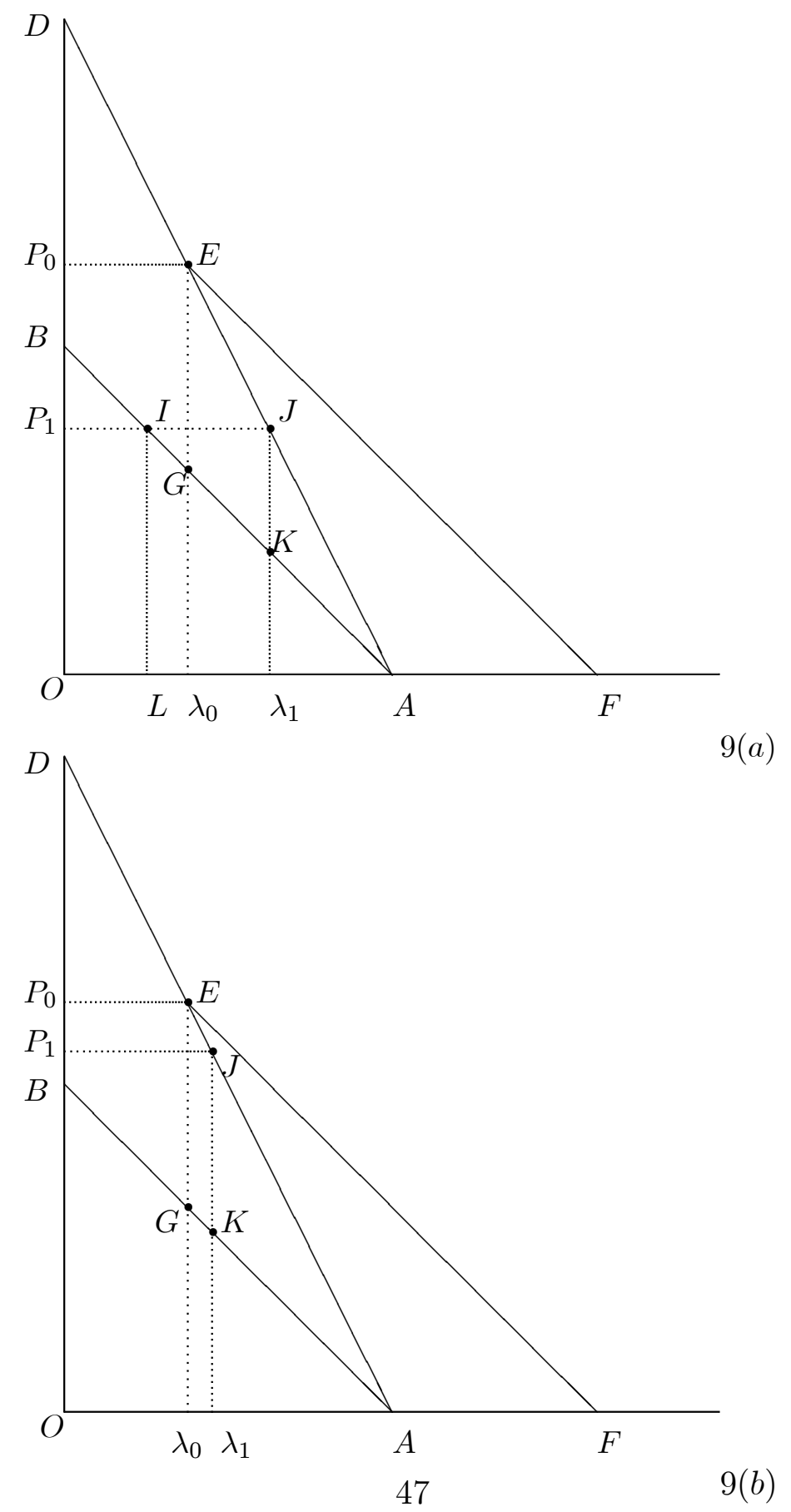
current income. All others need credit to purchase the durable. Only those with a lifetime income in excess of the price, that is, individuals whose productivity and current income is greater than $\frac{P_{0}}{2}$, will get the credit equal to the difference between their current income and the price. Thus, the demand for credit is given by the area $P_{0} E G B$ in Figure 9 .

Supply of credit comes from two sources: half of the profits (share of the young), and individuals whose current income is less than $\frac{P_{0}}{2}$. The profit share of the young is $\frac{1}{2}\left(P_{0}-c\right) q_{0}$, while the supply of credit by poor individuals is given by the area of the triangle $G \lambda_{0} A$. Thus, total supply of credit will be the area $G \lambda_{0} A+\frac{1}{2}\left(P_{0}-c\right) q_{0}$. Note that along the line $B A, P=1-q$, and along the line $D A, P=2-2 q$.

The demand for credit is

$$
\begin{aligned}
P_{0} E G B & =\left(P_{0}-1\right) \lambda_{0}+\frac{1}{2}\left(1-\left(1-\lambda_{0}\right)\right) \lambda_{0} \\
& =\frac{1}{8}+\frac{1}{8} c-\frac{3}{32} c^{2}
\end{aligned}
$$

and the supply of credit is

$$
\begin{aligned}
G \lambda_{0} A+\frac{1}{2}\left(P_{0}-c\right) q_{0} & =\frac{1}{2}\left(1-\lambda_{0}\right)\left(1-\lambda_{0}\right)+\frac{1}{2}\left(P_{0}-c\right) \lambda_{0} \\
& =\frac{1}{8}+\frac{1}{8} c+\frac{1}{32} c^{2}+\frac{1}{2}\left(P_{0}-c\right) \lambda_{0} .
\end{aligned}
$$

Note that the first term, $\frac{1}{8}+\frac{1}{8} c+\frac{1}{32} c^{2}$, exceeds total demand for credit, $\frac{1}{8}+\frac{1}{8} c-\frac{3}{32} c^{2}$, and the second term is strictly positive. Therefore, $r=0$ is the equilibrium interest rate in period 0 . 


\section{A.2.2 Period 1: Low Price Period}

In the following period, the demand curve is given by $D E F$, and the monopolist chooses a lower price and serves a larger proportion of its young consumers. The flatter part of the demand curve can be expressed as

$$
\hat{D}=2-\lambda_{0}-P=\frac{3}{2}+\frac{c}{4}-P
$$

The optimal price, $P_{1}$, can be found by solving

$$
\underset{P_{1}}{\operatorname{Max}}\left(\frac{3}{2}+\frac{c}{4}-P_{1}\right)\left(P_{1}-c\right)
$$

which results in

$$
\begin{aligned}
P_{1} & =\frac{3}{4}+\frac{5}{8} c, \\
q_{1} & =\frac{3}{4}-\frac{3}{8} c, \text { and } \\
\lambda_{1} & =1-\frac{\frac{3}{4}+\frac{5}{8} c}{2}=\frac{5}{8}-\frac{5}{16} c .
\end{aligned}
$$

Note that $P_{1}$ exceeds 1 if $c>\frac{2}{5}$, and it is less than 1 otherwise. Credit demand comes from the young who cannot afford the good based on their current income.

Figure $9(a)$ depicts the case for $c<2 / 5$, i.e., $P_{1}<1$. Then, individuals in the interval $L \lambda_{1}$ demand credit equal to the area of the triangle $I J K$

$$
\begin{aligned}
I J K & =\frac{1}{2}\left(\lambda_{1}-\left(1-P_{1}\right)\right)\left(P_{1}-\left(1-\lambda_{1}\right)\right) \\
& =\frac{1}{2}\left(\frac{5}{8}-\frac{5}{16} c+\frac{3}{4}+\frac{5}{8} c-1\right)^{2} \\
& =\frac{9}{128}+\frac{15}{128} c+\frac{25}{512} c^{2}
\end{aligned}
$$


When $P_{1}<1$ supply of credit comes from three sources: Supply from the rich, $B P_{1} I$, supply from the poor, $K \lambda_{1} A$, and the profit share of the young, $\frac{1}{2}\left(P_{1}-c\right) q_{1}:$

$$
\begin{aligned}
B P_{1} I+K \lambda_{1} A+\frac{1}{2}\left(P_{1}-c\right) q_{1} & =\frac{1}{2}\left(1-P_{1}\right)^{2}+\frac{1}{2}\left(1-\lambda_{1}\right)^{2}+\frac{1}{2}\left(P_{1}-c\right) q_{1} \\
& =\frac{49}{128}-\frac{41}{128} c+\frac{161}{512} c^{2}
\end{aligned}
$$

In this case the difference between supply and demand, $\frac{5}{16}-\frac{7}{16} c+\frac{17}{64} c^{2}$, is positive at all $c \in[0,1]$. Therefore, $r=0$ is the equilibrium interest rate.

What if $c>2 / 5$ ? In this case, as in period 0 , no individual can afford the good without borrowing. Figure $9(b)$ depicts the case for $c>2 / 5$. Demand for credit is given by the area $P_{1} J K B$ :

$$
\begin{aligned}
P_{1} J K B & =\left(P_{1}-1\right) \lambda_{1}+\frac{1}{2}\left(1-\left(1-\lambda_{1}\right)\right) \lambda_{1} \\
& =\left(\frac{3}{4}+\frac{5}{8} c-1\right)\left(\frac{5}{8}-\frac{5}{16} c\right)+\frac{1}{2}\left(\frac{5}{8}-\frac{5}{16} c\right)^{2} \\
& =\frac{5}{128}+\frac{35}{128} c-\frac{75}{512} c^{2}
\end{aligned}
$$

Now, supply comes from only two sources, the poor and profits going to the young as no one can afford the good on their current income alone: $K \lambda_{1} A+\frac{1}{2}\left(P_{1}-c\right) q_{1}:$

$$
\begin{aligned}
K \lambda_{1} A+\frac{1}{2}\left(P^{1}-c\right) q^{1} & =\frac{1}{2}\left(1-\lambda_{1}\right)^{2}+\frac{1}{2}\left(P_{1}-c\right) q_{1} \\
& =\frac{1}{2}\left(1-\left(\frac{5}{8}-\frac{5}{16} c\right)\right)^{2}+\frac{1}{2}\left(P_{1}-c\right) q_{1} \\
& =\frac{9}{128}+\frac{15}{128} c+\frac{25}{512} c^{2}+\frac{1}{2}\left(P_{1}-c\right) q_{1} .
\end{aligned}
$$


Even without supply coming from profits, supply exceeds demand for all $c$, therefore $r=0$ is still an equilibrium.

\section{A.2.3 Cycles With Credit Markets}

Finally we show that this economy has a two-period cycle with credit markets. The flatter part of the demand curve in period 2 is

$$
\begin{aligned}
\hat{D}_{2} & =2-\lambda_{1}-P \\
& =\frac{11}{8}+\frac{5}{16} c-P,
\end{aligned}
$$

and the optimal price on this demand curve is

$$
\hat{P}_{2}=\frac{11}{16}+\frac{21}{32} c .
$$

As a result a firm produces

$$
\hat{q}_{2}=\frac{11}{16}-\frac{11}{32} c,
$$

and makes a profit of

$$
\hat{\pi}_{2}=\left(\frac{11}{16}-\frac{11}{32} c\right)^{2}
$$

while it can make a profit of

$$
\begin{aligned}
\pi^{*} & =\left(1-\frac{c}{2}\right)\left(\frac{1}{2}-\frac{c}{4}\right) \\
& >\hat{\pi}_{2} .
\end{aligned}
$$

by serving on the steeper part of the demand curve. Therefore, this economy has two-period cycles. 